\title{
CHARACTERISTIC OF FIBER LASER SURFACE HARDENING DEPTH OF AZ31B MAGNESIUM ALLOY
}

${ }^{*}$ Eman Ali Ashur ${ }^{1}$
Sahib Mohammed Mahdi ${ }^{2}$

1) MSc student, Material of engineering department, Al-Mustansiriya University, Baghdad, Iraq.

2) Asst. prof., Material of engineering department, Al-Mustansiriya University, Baghdad, Iraq.

\begin{abstract}
The present work shows the effect of laser surface hardening process for AZ31B Magnesium Alloy by using a Beam of Fiber Laser. One sample surface was exposed to a beam of fiber laser with laser parameters of (30 watt peak power, $20 \mathrm{KHz}$ work frequency, and $0.1 \mathrm{~ms}$ pulse duration) at a fixed wavelength of $1064 \mathrm{~nm}$. Hardness, roughness, and optical tests for the specimen were examined prior to and following the treatment with laser surface. Also, it has been indicated that the Hardness and Roughness regarding laser treated specimen were increased when compared to the untreated specimen. Furthermore, the laser melted surface layer specified enhancement in the significance of microhardness in comparison to the as received (untreated alloy), this is due to grains refining after laser surface hardening treatment.

This research also determines the Characteristic of depth penetration of the surface hardening, and the amount of depth due to fiber laser beam was about $(20.8 \mu \mathrm{m})$.
\end{abstract}

Keywords: AZ31B Magnesium Alloy, laser surface treatment, Roughness, Hardness, optical test, Fiber laser.

\section{Introduction}

The magnesium alloys have been defined as one of the major prospective and developed construction metals, also they are competing efficiently with the plastics, steels, and aluminum alloys due to their significant mechanical properties, also their technical alloys' low density, which provide them with important possibilities in a lot of applications, their density is approximately $\left(1.74 \mathrm{~g} / \mathrm{cm}^{3}\right)$, that has been one third low in comparison to that related to aluminum alloys and approximately $80 \%$ low in comparison to steel [1].

In spite of their distinctive properties, using magnesium alloys has been mainly restricted through their low corrosion resistance, poor tri-biological properties, and low hardness.

There is a need in different industries to improve the performance of the material's surface in corrosion environments which cannot be satisfied by traditional surface treatment and modifications. Therefore, for improving the properties related to material's surface, laser surface hardening has been used [2].

(LSH) requires rapid heating of the surface of a material through the laser beam, rapid hold at target temperature, in addition to the fast cooling due to the material's elevated thermal conductivity. Extremely focused laser beam will be locally heating up the surface of component in extremely little time to the hardening temperature $\left(>1000^{\circ} \mathrm{C}\right)$. When the laser beam is not working, heat will be transmitted into the work piece's base material (self-quenching), then becomes hard [3].

*Corresponding author: eman45113@gmail.com 
While (LSH) does not introduce significant modifications in changed surface regarding the $\mathrm{Mg}$ alloys, a few of the alloying elements might be evaporated. Width/depth of melting as well as the grain size in changed track is on the basis of scan speed, laser power, and laser spot's size (irradiation area) incident [4].

There have been a lot of researches on the laser treatment Behavior related to $\mathrm{Mg}$ alloy. For instance:

S.H. CHOWDHURY and D.L.CHEN (2012) examined the microstructure properties tests and adjusts the fatigue and tensile properties related to fiber laser welded AZ31B Mg-alloys with specific concentrations on the impact related to welding speed. Also, the laser treatment caused developing dendrites in the fusion zone in addition to columnar dendrites close to fusion zone, as well as divorced eutectic $\mathrm{Mg}_{17} \mathrm{Al}_{12}$ particles [5].

A study conducted by (Yee-Hsian Ho, et al.) (2014) examined the impact of laser surface modification on AZ31B Mg-alloys surface on resulting bio-wet ability has been studied via contact-angle measurements as well as certain co-relations have been created between micro-structure (grain size), surface chemical composition, surface energy, and surface roughness. Also, the approach of laser surface modifications has been simulated for the purpose of facilitating the prediction related to temperature, resultant solidification/cooling rates within different laser conditions [6].

\subsection{Magnesium Alloys}

Mg alloys are desirable metals because of its excellent specific features, like low density as well as high specific strength, make it suitable for the transport industry alloys. Magnesium alloys meet the requirements for low specific weight items with outstanding machining capabilities and good recycling capabilities.
Magnesium alloys have very good mach inability and versatility in processes [7].

One serious drawback of $\mathrm{Mg}$ alloys has been their corrosion performance. The low corrosion resistance regarding $\mathrm{Mg}$ and $\mathrm{Mg}$ alloys can be a main disadvantage; a lot of attempts have been made for enhancing the resistance [8].

AZ31B Alloy is a wrought magnesium alloy with good room temperature and ductility combined with resistance to corrosion and welding capability. AZ31 used in a lot of applications such as medical implants, aircraft fuselages, mobile phones and laptop cases, speaker cones and concrete equipment [9].

\subsection{Fiber Laser Beam}

Fiber laser can be defined as a laser with optical fiber which is doped with rare earth elements like (thulium, neodymium, dysprosium, erbium, and ytterbium) as active gain medium. It is a compact laser ideally designed elevated optical and electrical performance, good beam strength, reliability, also elevated peak energy by amplifying specific wavelengths within the optical fibers. It is converts the laser pump's coherent wavelength into separate ones. These optical amplifiers which use a doped optical fiber as a means of gaining an optical signal [10].

Recently, Fiber lasers have got attention among the various types of lasers, since in industrial applications; this type of laser has several advantages: compact size of laser equipment, elevated efficiency of laser generation, reduced costs of maintenance, versatile beam delivery, and high power with low beam divergence [11]. 
Table 1. Show comparison for Fiber, YAG and CO2 lasers [12].

\begin{tabular}{cccc}
\hline Laser Type & Fiber laser & YAG & CO2 laser \\
investment & Good & Good & Excellent \\
Footprint & Excellent & Poor & Poor \\
Maintenance & Excellent & Poor & Poor \\
Reliability & Excellent & Poor & Poor \\
efficiency & Good & Fair & Poor \\
processing & Excellent & Fair & Fair \\
Beam quality & Excellent & Fair & Good \\
\hline
\end{tabular}

\subsection{Laser Surface Hardening (LSH)}

LSH is considered as one of processes related to surface hardening which might be utilized often in recent applications to majorly the whole metallic materials. Laser beam is designed to harden the necessary portion of the material to the localized area. High intensity laser radiation is used to heat metal surface. Due to high heat transfer speeds, temperature emerge which It results in rapid conduction cooling. It makes the transformation of the cycle without having to quench externally. The majorly applied lasers for hardening are CO2, Nd-YAG, Fiber and diode lasers [13].

The process of LSH have been majorly applied in bio-medical applications, turbines and cams, slide movements, local mould hardening, gear wheels, tools parts, shafts, and valves [14].

The main advantages of (LSH) are:

- Low energy consumption

- A hardened surface is self-quenched

- LSH is clean without any quenching media
- Beam guide can be streamlined over work piece surface

- For small parts heat treatment might be performed [15].

\subsection{Penetration depth}

It can be considered as significant factor that is critical to LSH's quality. Penetration of laser depends upon:

1. Absorption and Scattering.

2. Depth of penetration increases with wave length.

3. Amount of Scattering is inversely proportional to wave length [16].

\section{Experimental Work}

\subsection{Materials}

Chemical composition of the AZ31B Mg alloy specimen is mentioned in Table (1).

Table 2. The AZ31B Mg alloy specimen's chemical composition:

\begin{tabular}{cccccccc}
\hline Element & $\mathrm{Al}$ & $\mathrm{Zn}$ & $\mathrm{Mn}$ & $\mathrm{Si}$ & $\mathrm{Fe}$ & $\mathrm{Cu}$ & $\mathrm{Mg}$ \\
$\mathrm{Wt} \%$ & 2.9 & 0.9 & 0.36 & 0.013 & 0.0024 & 0.0089 & Balance
\end{tabular}

\subsection{Specimens:}

Disk shape specimens are used with $25 \mathrm{~mm}$ diameter and $2.5 \mathrm{~mm}$ thickness. Figure (1) show the specimen sample.
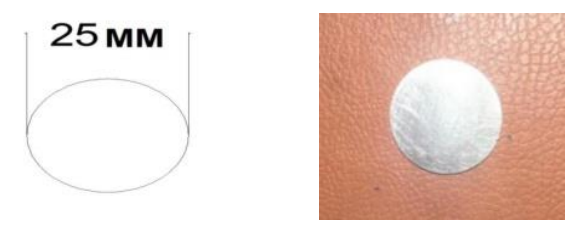

Figure 1. Shape and dimensions of AZ31B Mg Alloy sample 


\subsection{Experimental procedure}

Response of the specimens to the laser surface hardening process was found, and obtain the desired results, the laser parameters were chosen. The parameters of the laser beam that have chief affected during the experiments in this work are power (30) Watt, frequency (20) $\mathrm{kHz}$ and pulse duration (0.1) $\mathrm{ms}$.

with constant scanning speed $(1000 \mathrm{~mm} / \mathrm{s})$.

The best laser parameters found by the experimental tests are shown in the Table (3)

Table 3. Best fiber laser working parameters

\begin{tabular}{lc}
\hline Pulse duration(ms) & 0.1 \\
Full peak power(Watt) & 30 \\
Work frequency $(\mathrm{KHz})$ & 20
\end{tabular}

\section{Results and Discussion}

\subsection{Roughness Test}

The surface roughness is of high importance to assess the product's surface quality and measuring it. Roughness affects product functionality including lubrication and friction, fatigue, heat transfer, break, and consistency related to product should be high. [17]

Results for the roughness test were discussed in order to assess its affect in table (4):

Table 4 . Surface Roughness Test Results

\begin{tabular}{lcc} 
Specimens state & $\mathrm{Ra}(\mu \mathrm{m})$ & $\mathrm{Ra}$ av. $(\mu \mathrm{m})$ \\
As received & $1.55,1.69,1.31$ & 1.51 \\
Fiber Laser & $5.59,5.01,5.82$ & 5.47 \\
\hline
\end{tabular}

The average value of Roughness test for untreated AZ31B alloy specimen was $(1.51 \mu \mathrm{m})$, while the average value of Roughness test for laser surface hardening treatment specimen become $(5.47 \mu \mathrm{m})$. For these results it's clear that the surface roughness is rise due to laser beam incidence.

\subsection{Micro hardness Test}

Hardness is a material property which enables it to withstand plastic deformation [18].Samples have been ground with a silicon carbide paper before the microhardness test then polished with cloth paper. the hardness regarding AZ31B was specified for examining the impact of laser fiber beam on acquired value.

Results for the microhardness test were recorded and discussed in order to assess its effect in table (5).

Table 5 . Vickers Microhardness test results

$\begin{array}{lcc}\text { Specimens state } & \mathrm{HV} \mathrm{kg} / \mathrm{cm}^{2} & \mathrm{HV} \mathrm{kg} / \mathrm{cm}^{2} \mathrm{av} . \\ \text { As received } & 111.4,86.61,90.5 & 96.17 \\ & & \\ \text { Fiber Laser } & 341.9,244.8,289.4 & 292.03\end{array}$

The average value of Hardness test for untreated AZ31B alloy specimen was $\left(96.17 \mathrm{HV} \mathrm{kg} / \mathrm{cm}^{2}\right.$ av), while the average value of Hardness test for laser surface hardening treatment specimen

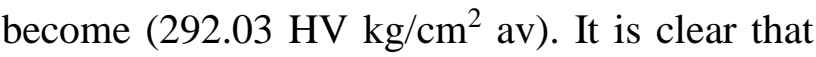
there is higher increase in hardness value of fiber laser surface hardening specimens.

\subsection{OPTICAL TEST}

An optical microscope examined the microstructure of the specimens after processes of grinding, polishing, and etching.

the microstructure of untreated and for laser surface hardening treatment specimens was studied by examining the surface and the cross 
sectional area of specimens using an optical microscope with magnification (100X), figures (5, 6 and 7) shows the microstructure of the as received specimen, after laser surface hardening and the section through the surface of laser treated.

For figure (2) of as received AZ31B alloy it is clear that there are small uniform polygonal grains with average Vickers microhardness $\left(96.17 \mathrm{~kg} / \mathrm{cm}^{2}\right)$.

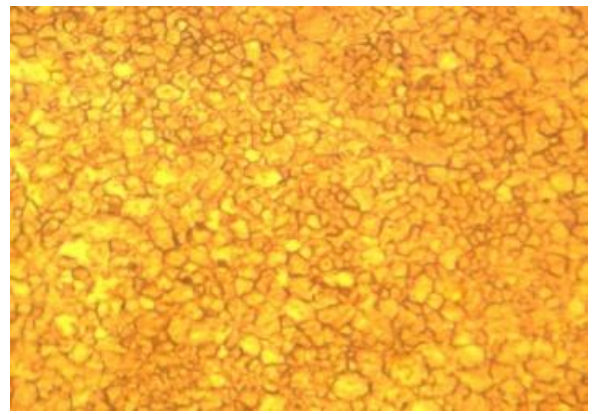

Figure 2. Show the microstructure of as received AZ31B alloy. $100 \mathrm{X}$

While figure (3) show the microstructure of AZ31B alloy after surface heat treatment with fiber laser, it is clear that there is a refining in grains due to laser treatment and for that there is an increase in hardness up to $\left(292 \mathrm{~kg} / \mathrm{cm}^{2}\right)$.

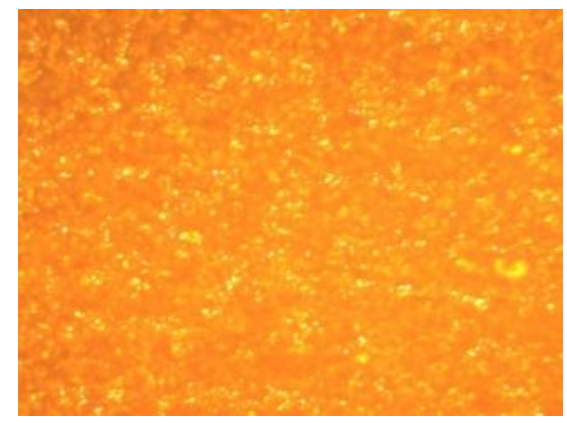

Figure 3. Show the microstructure of fiber laser surface hardening for AZ31B alloy. 100X

Figure (4) show the section through the specimen of AZ31B alloy after surface hardening with fiber laser for determines the depth penetration occurs in the metal surface during the laser surface hardening process (LSH). It shows that the surface layer hardening thickness is $(20.8 \mu \mathrm{m})$. There is a uniform thickness with some penetrate like pins. Where (HAZ) is very narrow.

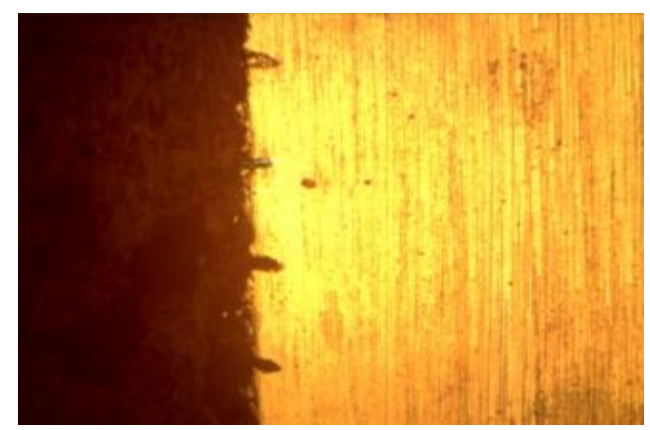

Figure 4. Show section through the fiber laser surface hardening for AZ31B alloy. 100X

\section{Conclusions}

1. The Laser surface hardening of AZ31BSpecimens has high Roughness value comparing to the As Received Specimens. For that fiber laser beam leads to increase surface roughness.

2. The hardness value of Laser surface hardening of AZ31B Specimens was increased due to fine grains occurs that introduced from the super cooling of metal surface fiber laser treated.

3. By determining the best laser parameters, the depth penetration was measured through the optical microscope test. It is very good depth for the precision parts because it is very thin.

4. Fiber laser beam is suitable for case hardening, because it can be controlled and give uniform layer and flawless.

5. It was found that the Microstructure observation by optical microscope exhibited refining in grains of AZ31B alloy after laser surface treatment.

\section{Acknowledgements}

The authors like to thank Al-Mustansiriyah University (www.upomustansiriyah.edu.iq) (Baghdad-Iraq) for its support in this work. 


\section{Conflict of interest}

The authors would like to confirm that there is no conflict of interest.

\section{Abbreviations}

List of symbols are inserted and clarified below

S Mpa Stress

$\mathrm{Ra} \mu \mathrm{m} \quad$ roughness

wt.\% Weight percent $\%$

$\mathrm{HV} \mathrm{kg} / \mathrm{cm}^{2}$ Vickers microhardness

$\mathrm{Hz} \quad$ Frequency

$\mu \mathrm{m} \quad$ length

watt Power

$\mathrm{g} / \mathrm{cm}^{3} \quad$ density

\section{References}

[1] W.A. Monteiro, S.J. Buso and L.V. da Silva (2012) "Application of Magnesium Alloys in Transport" Submitted: November 17th 2011Reviewed: April 21st.

[2] Hanshan dong (2010)"surface engineering of light alloys aluminum, magnesium and titanium alloys" wood head publishing limited.

[3]Muna Kh. Abbes \& Adel. K. Mahmud, (ICEMS-2016)" Laser surface treatment of Al12\%Si alloy" Selection and Peer-review under responsibility of International Conference on Recent Trends in Engineering and Material Sciences.

[4] Sound arap and iansan thanak rishnan and narendra B. dahotre (2013). "laser surface hardening" page (476-502).

[5]S. H. ChowdhuryD. L. ChenS. D. BholeE. Po widajko C. WeckmanY. Zhou June (2012)"Fiber Laser Welded AZ31 Magnesium Alloy: The Effect of Welding Speed on
Microstructure and Mechanical Properties"

Volume 43, Issue 6, pp (2133-2147).

[6] Yee-Hsien Ho, Hitesh D Vora, Narendra B

Dahotre Published at September 8, (2014) "Laser surface modification of AZ31B Mg alloy for bio-wet ability"

[7] K. U. Kainer, 22Jun. (2004) "Magnesium alloys and technology", Wiley online Library.

[8] Wang, Estrin , Song ,and Zúberová, Nov. (2007) "The effect of pre-processing and grain structure on the biocorrosion and fatigue resistance of magnesium alloy AZ31"

[9] ASM International Introduction of Magnesium Alloys. In C. moos braggers (Ed.), (2017) Engineering Properties of Magnesium Alloys. (pp. 1-10).

[10] Breglio Giovanni Candidato\&Macera Giuseppe Mart, "Principles, typologies and applications of Fiber Lasers" research gate.

[11] L. Quintino, A. Costa, R. Miranda, D. Yapp IDMEC B. Shiner January ( 2010)" Welding with high power fiber lasers - a preliminary study", "Fiber Lasers for Material Processing”, ISSN: 1662-9752, vol. 636-637, pp $(592-596)$.

[12] John Powell\& A.F. H .Kaplan January (2012) ":comparison of Fiber laser, CO2 laser"

[13] Muna Kh. Abbes \& Adel. K. Mahmud, (ICEMS-2016) "Laser surface treatment of Al12\%Si alloy" Selection and Peer-review under responsibility of International Conference on Recent Trends in Engineering and Material Sciences. 
[14] W.M. Steen, J. Mazumder (2015) ," Laser Material Processing”, $4^{\text {th }}$ edition, SpringerVerlag London.

[15] Laser surface hardening: a review (2011) P. Dines Babu and K.R. Balasubramanian Int. J. Surface Science and Engineering, Vol. 5, Nos. 2/3, 2011131.

[16] K. Palaniradja, N. Alagumurthi and V. Soundararajan (2010) "Hardness and Case Depth Analysis through Optimization Techniques in Surface Hardening Processes" Pondicherry - 605 014, India, The Open Materials Science Journal.

[17] Mohamad Rais Bin Ramli, November (2009)."Instigation of Surface Roughness of Mild Steel using Coated Carbide Cutting Tools", University MalaysiaPahang, Malaysia,

[18] Warren Blackadder, Book, April (2013) "MEM30007A - Select common Engineering Materials" topic 3 pp. 64, $2^{\text {nd }}$ Edition 1. 